\title{
Homeopathic Remedies in COVID-19: Prognostic Factor Research
}

\author{
Raj Kumar Manchanda ${ }^{1}$ Anjali Miglani ${ }^{1} \quad$ Meeta Gupta $^{1}$ Baljeet Singh Meena ${ }^{1}$ Vishal Chadha ${ }^{1}$ \\ Franco Joseph ${ }^{1}$ Amrit Kalsi ${ }^{1}$ Pramod Konthembath ${ }^{1}$ Kavita Sharma ${ }^{1}$ Kamsali Nadigadda Rama ${ }^{1}$ \\ Prabhjeet Kaur $^{1}$ jithesh Thavarayil Kannoth ${ }^{1}$ Cheshta Nagrath ${ }^{1}$ Anju Jethani ${ }^{1}$ \\ Shajimol Nellikka Aniyeri ${ }^{1}$ Anu Chawla ${ }^{1}$ Malaya Kumar Ray ${ }^{1}$ Manjula Ghuliani ${ }^{1}$ \\ Ram Kumar Kudiyarasu ${ }^{1}$ Shruti Naskar ${ }^{1}$ Sudha Bala ${ }^{1}$ Brender Sharma ${ }^{1}$
}

1 Health and Family Welfare Department, Directorate of AYUSH, Government of National Capital Territory of Delhi, New Delhi, India Homeopathy 2021;110:160-167.
Address for correspondence Raj Kumar Manchanda, BHMS, MD (Hom), MBA (Health Care), Directorate of AYUSH, CSC-III, First Floor, B-Block, Preet Vihar, Delhi 110092, India (e-mail: rkmanchanda@gmail.com).

\begin{abstract}
Keywords

- COVID-19

- homeopathy

- prognostic factor research

- likelihood ratio

Background/Objective Coronavirus disease 2019 (COVID-19) is a new disease; its clinical profile and natural history are evolving. Each well-recorded case in homeopathic practice is important for deciding the future course of action. This study aims at identifying clinically useful homeopathic remedies and their prescribing symptoms using the prognostic factor research model.

Methods This was an open-label, multi-centric, observational study performed from April 2020 to July 2020 at various public health care clinics. The data were collected prospectively from clinical practice at integrated COVID-19 care facilities in India. Good-quality cases were selected using a specific set of criteria. These cases were analyzed for elucidating prognostic factors by calculating the likelihood ratio (LR) of each frequently occurring symptom. The symptoms with high $L R$ values $(>1)$ were considered as prescribing indications of the specific remedy.

Results Out of 327 COVID-19 cases reported, 211 met the selection criteria for analysis. The most common complaints were fatigue, sore throat, dry cough, myalgia, fever, dry mouth and throat, increased thirst, headache, decreased appetite, anxiety, and altered taste. Twenty-seven remedies were prescribed and four of them-Arsenicum album, Bryonia alba, Gelsemium sempervirens, and Pulsatilla nigricans-were the most frequently used. A high LR was obtained for certain symptoms, which enabled differentiation between the remedies for a given patient.

Conclusion Homeopathic medicines were associated with improvement in symptoms of COVID-19 cases. Characteristic symptoms of four frequently indicated remedies have been identified using prognostic factor research, findings that can contribute to accurate homeopathic prescribing during future controlled research in COVID-19.
\end{abstract}

received

October 30, 2020

accepted after revision

November 30, 2020

published online

April 30, 2021 (c) 2021. The Faculty of Homeopathy.

All rights reserved.

Georg Thieme Verlag KG,

Rüdigerstraße 14,

70469 Stuttgart, Germany
DOI https://doi.org/

10.1055/s-0041-1725989. ISSN 1475-4916. 


\section{Introduction}

Coronavirus disease 2019 (COVID-19) cases were identified in early December 2019 in China, and the first case in India was reported on January 30, 2020, in Kerala. ${ }^{1}$ Since then, India has been grappling with the ever-increasing number of cases and various approaches for the containment of infection. India has a unique health care system, with a pluralistic approach wherein Ayurveda, Yoga and Naturopathy, Unani, Siddha, and Homeopathy (AYUSH) systems have been integrated in the primary health care provided through wellness clinics across the country. The public health services are free of cost, both at primary and secondary levels of health care. Of these, homeopathic services are available at approximately $30 \%$ of centers and cater to about one-fifth of the annual patient turnover. These services are immensely popular, even among the AYUSH systems, and are being optimally utilized. $^{2}$ In Delhi too, the Government offers integrated health care services at their health centers, where Ayurveda, Unani and Homeopathy services co-exist with conventional services under one roof. Patients can choose any one or more services at their discretion.

Presently, 107 Delhi Government wellness centers have integrated homeopathy facilities. In a survey of these clinics, $85.2 \%$ of patients felt that the homeopathy services are essential and a majority of conventional doctors felt that homeopathy clinics within the same premises are beneficial. ${ }^{3}$ Respiratory ailments are among the top 10 diseases reported in the annual morbidity profiling of patients visiting these centers. ${ }^{2}$ Studies have shown that homeopathic medicines have a beneficial effect in influenza-like illnesses (ILIs) $)^{4,5}$ but their effectiveness in COVID-19 is yet to be established.

It is suggested that homeopaths should take full advantage of this rare opportunity and aim to demonstrate homeopathy's efficacy in COVID-19 based on the modern methods of fundamental and clinical research. ${ }^{6}$ The homeopathy community can analyze the available data about potential medicines used for ILI. Medicines such as Bryonia alba, Calendula officinalis and Passiflora incarnata might prove to be inhibitors of angiotensin-converting enzyme 2 , and are worth investigating for the treatment of COVID-19. ${ }^{7}$ Randomized controlled trials (RCTs) are considered to be the gold standard in clinical research and assume the highest importance in evidence-based medicine. A well-designed randomized placebo-controlled study requires prior experience and outcome documentation.

Observational studies provide such prior experience, as they describe "real-world" care settings and allow for a more generalized and robust estimation of effects in clinical practice; they are thus an important approach to assist in designing RCTs. ${ }^{8}$ The need is for a series of systematic studies that includes collection and analysis of good-quality cases treated with homeopathy. Prognostic factor research is an important technique for the analysis of cohorts of such cases. "Prognostic factor" means a characteristic of a patient that can be used to estimate the chance of recovery from a disease. In homeopathy, doctors prescribe medicines based on the specific symptoms of the patients and expect that a medicine will work based on their experience that specific symptoms of the patient indicate specific medicines; the prevalence of such symptoms is higher in a population responding well to a specific medicine than in the remainder of the population. ${ }^{9,10}$ Such symptoms are considered as prognostic factors and can play an important role in accurately prescribing medicines during RCTs.

The Government of India has pooled all available resources, including the AYUSH sector, for the management of the COVID-19 pandemic using scientific, evidence-based, solutions and with a caution against false claims. ${ }^{11}$ An interdisciplinary AYUSH research and development task force has been constituted with the objective of identifying potential preventive and therapeutic approaches within these systems. $^{12}$

Homeopathic doctors have been posted in COVID Care Centers and COVID Testing Centers as part of a team with conventional doctors and have been authorized to provide an integrated care package including homeopathy for COVID-19 patients.

\section{Objectives}

The primary objective was to identify clinically useful homeopathic remedies and their characteristic indications using the prognostic factor research model for COVID-19. The secondary objective was to catalog the symptomatology of the disease.

\section{Methods}

\section{Study Design and Settings}

This was an open-label, multi-centric, observational study performed from April 2020 to July 2020. Patients treated were confirmed COVID-19 positive cases, defined as those with positive results on real-time reverse-transcriptasepolymerase-chain-reaction (RT-PCR) assay of nasal and pharyngeal swab specimens. ${ }^{13}$ Patients who gave informed verbal consent to take homeopathic medicines were prescribed based on their individualized symptoms.

Medicines procured from a GMP-certified firm were used. The homeopathic remedies prescribed in all these patients were in addition to their standard conventional treatment as advocated by the Ministry of Health and Family Welfare, Government of India. The conventional drugs were mainly symptomatic, such as paracetamol, antibiotics, cetirizine, cough syrups, or multi-vitamins. No patient was given corticosteroids or antivirals in this group. Homeopathic remedies were prescribed based on individualization at the discretion of treating doctors. Twenty-eight qualified and experienced homeopathic doctors, working at 23 homeopathic clinics operational at conventional health centers and hospitals, recorded cases in a specially designed format and analyzed each patient's data for prescribing a specific remedy.

Formal approval for the study was obtained from the relevant research ethics committee and was conveyed by letter no: F/No5(11)/93/NHMC/Academic/PG 2007 onward/ 
1913, dated June 2, 2020, allowing the publication of these data after removing the personal details of the patients.

\section{Participants}

All RT-PCR-confirmed COVID-19 patients, treated at COVID Care Centers and in home isolation, were studied. All patients with mild to moderate disease were considered. Mild cases were patients with uncomplicated upper respiratory tract infection without evidence of breathlessness or hypoxia (normal oxygen saturation). Moderate cases were those with pneumonia but no signs of severe disease, $\mathrm{SpO}_{2}$ $<94 \%$ (range $90-94 \%$ ) on room air, and respiratory rate more than or equal to 24 per minute. ${ }^{14}$ Patients with co-morbidities were also included in the study.

\section{Variables}

The variables were:

- Demographic profile and clinical presentation of patients.

- Homeopathic medicines and their indications that can be used as prognostic factors.

\section{Data Source}

Doctors were trained in data collection at the start of the study. A bespoke Excel spreadsheet was shared with all doctors who then, on a daily basis, added data of their respective cases from their centers. The spreadsheet contained 71 fields covering a spectrum of COVID-19 symptoms. It also contained fields related to the mental and emotional states of patients to record associated fear and/or anxiety. ${ }^{15,16}$ The prescriptions were based on the individualization of symptoms. The spreadsheet also contained fields for detailed follow-ups and outcomes after 1 week of treatment. The identifying information of patients was kept confidential at each center by recording their registration numbers instead of names.

Follow-up was done daily until complete resolution of symptoms or up to a week. Patients who were in home isolation were followed up telephonically every day. In each follow-up, the patient was asked about any change in their symptom intensity and overall well-being, as is done in any homeopathic case follow-up in a regular setting. The Outcome in Relation to Impact on Daily Living (ORIDL) scale, which ranges from -4 to +4 , was used for patient assessment at each follow-up. ${ }^{17}$

Regular online meetings with all doctors were organized to ensure the quality of data collection. The data were regularly monitored, and any issues related to outliers, misreported or missing data, etc. were quickly resolved. This was done to ensure consistency in data, maintain the good quality of cases, and to reduce bias.

An important challenge in prognostic factor research is establishing causality between medicine and improved health, as the cure may be due to the effect of the prescribed homeopathic medicine or other factors such as spontaneous and natural recovery or placebo effect. The following selection criteria were adopted for identifying good-quality cases:

- Only those cases with a reported outcome of ORIDL +3 or +4 , and within 7 days of starting homeopathic treatment, in both chief complaint and general well-being, as this is considered as a desirable effect of the homeopathic prescription.

- Improvement began within a few hours of starting homeopathic treatment. Twenty-four hours from the start of treatment was considered as cut-off time.

- Continuing improvement after repeated doses of the selected remedy.

After data collection on the spreadsheet was complete, each of the above cases was further reviewed using certain domains of the Modified Naranjo Criteria for assessing causal attribution of clinical outcomes. ${ }^{18}$ Out of 10 domains, only the following four domains were considered:

Domain 1: Was there an improvement in the main symptom or condition for which the homeopathic medicine was prescribed?

Domain 2: Did the clinical improvement occur within a plausible time-frame relative to the drug intake?

Domain 5: Did overall well-being improve?

Domain 10: Did repeat dosing create similar clinical improvement?

Cases with inadequate information or where causality could not be established were excluded from the analysis. Mild to moderate cases are known to improve spontaneously in 10 to 14 days; therefore, the cut-off time for assessment was set as 7 days, to eliminate, as far as possible, cases with spontaneous recovery.

Cases with the following attributes were excluded from the analysis (-Fig. 1)

- Inconclusive or unconfirmed RT-PCR report.

- Drop-out cases/lost to follow-up/incomplete cases/inadequate information.

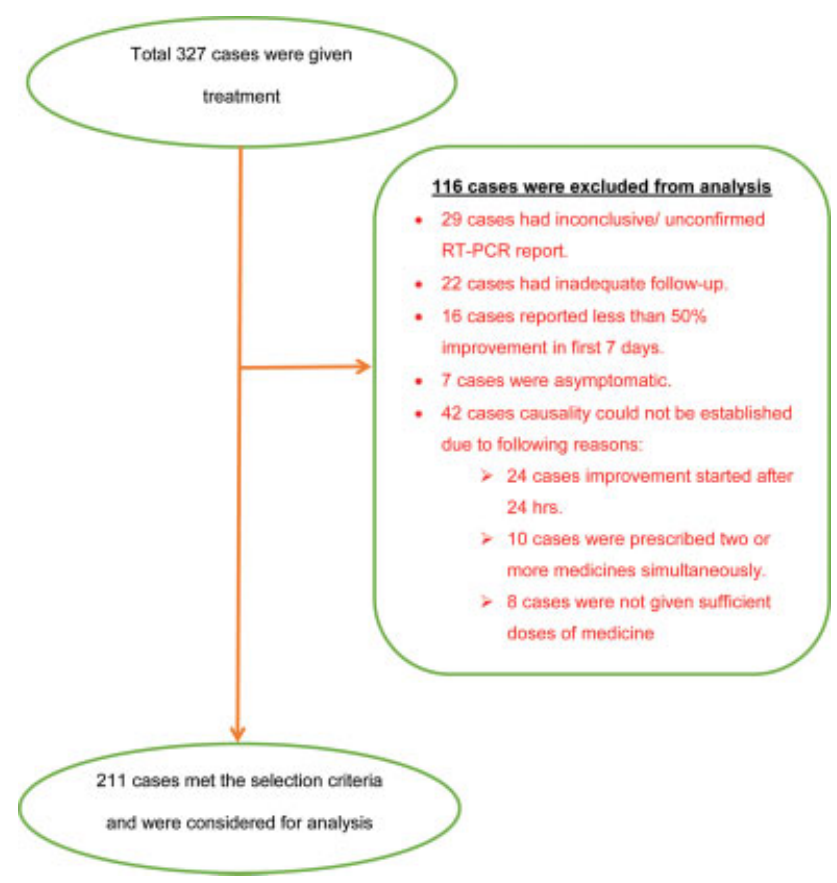

Fig. 1 Flowchart of the study. 
- Asymptomatic patients: i.e., tested positive but without any symptoms, as it was not possible to make any assessment.

- Two or more medicines used simultaneously. In such cases "which medicine worked" was difficult to assess and specific causality could not be established.

- Cases in which only one or two doses of a medicine were given, and it was not possible to relate improvement to these doses.

\section{Statistical Methods}

Prognostic factor analysis is based on the calculation of likelihood ratio (LR) to improve the reliability of prescriptions for future studies. It is expressed in a statistical formula known as Bayes' theorem: posterior odds $=\mathrm{LR} \times$ prior odds, where $\mathrm{LR}=$ (prevalence in the target population) $\div$ (prevalence in the remainder of the population). The target population is the population in which the medicine has a curative effect. $^{9}$

The LR of a symptom indicates a change in the chance of curative action of that medicine when that symptom is present in a patient. If $L R$ is $>1$, it implies that the chance that the medicine will be effective increases if that symptom is present. ${ }^{9}$ The higher the LR, the more strongly the medicine is indicated for that symptom. If the $95 \%$ confidence interval $(95 \% \mathrm{CI})$ of $\mathrm{LR}$ does not contain 1 (i.e., the lower value of the range is not less than 1 ), then it is considered meaningful.

\section{Results}

A total of 327 (203 male, 124 female) patients with COVID-19 were treated with adjunct homeopathic remedies; the majority were in the age range 18 to 60 years ( - Table 1 ). All cases showed improvement of varying degrees and no adverse reactions were noticed. A total of 298 cases were confirmed for COVID-19 via an RT-PCR-positive test result. Two hundred

Table 1 Demographic data $(n=327)$

\begin{tabular}{|l|l|l|}
\hline \multirow{4}{*}{ Gender } & Male & 203 \\
\cline { 2 - 3 } & Female & 124 \\
\hline \multirow{4}{*}{$\begin{array}{l}\text { (in years) } \\
\text { Contact history }\end{array}$} & $<18$ & 23 \\
\cline { 2 - 3 } & $18-60$ & 277 \\
\cline { 2 - 3 } & $>60$ & 27 \\
\cline { 2 - 3 } & Yes & 244 \\
\hline \multirow{3}{*}{ Co-morbidity } & No & 83 \\
\cline { 2 - 3 } & Absent & 75 \\
\hline \multirow{3}{*}{ Severity } & Mild & 252 \\
\cline { 2 - 3 } & Moderate & 296 \\
\hline \multirow{2}{*}{$\begin{array}{l}\text { Homeopathic } \\
\text { treatment }\end{array}$} & Single medicine given & 258 \\
\cline { 2 - 3 } & Two or more medicines given & 69 \\
\hline \multirow{2}{*}{$\begin{array}{l}\text { Status of RT-PCR } \\
\text { after treatment }\end{array}$} & Negative & 35 \\
\cline { 2 - 3 } & Not done & 292 \\
\hline
\end{tabular}

and forty-four patients had a history of contact with confirmed COVID-19 cases either at home or at the workplace. Two hundred and ninety-six patients had mild disease ( - Table 1 ).

A total of 258 patients were prescribed a single homeopathic remedy, whilst in 69 cases two or more homeopathic remedies were sequentially prescribed as per need. RT-PCR testing was done after homeopathic treatment in 35 cases after 2 to 3 weeks, and all became negative. Testing could not be done in other cases due to revised guidelines according to which a patient could be discharged after 10 days of symptom onset and no fever for 3 days (in mild cases) and absence of fever without antipyretics, resolution of breathlessness and no oxygen requirement (in moderate cases), and without the need for testing prior to discharge. ${ }^{19}$

A total of 211 cases met the selection criteria for improvement of COVID-19 symptoms and were analyzed. A total of 116 cases were excluded from the analysis, due to various reasons such as inadequate follow-up (22 cases), being asymptomatic (seven cases), or where causality could not be established (42 cases) (- Fig. 1).

The most common complaints were fatigue, sore throat, dry cough, myalgia, fever, dry mouth and throat, increased thirst, headache, decreased appetite, anxiety, and altered taste (-Table 2).

Twenty-seven medicines in varying potencies were prescribed, usually starting from $30 \mathrm{C}$ ( - Table 3 ). The medicines were repeated as per the need of an individual case, usually three to four times daily. In some cases, they were repeated more frequently. Arsenicum album and Bryonia alba were prescribed in 61 cases each. Gelsemium sempervirens was prescribed in 19 cases and Pulsatilla nigricans in 13 cases. Some less-known medicines, e.g., Magnesia muriaticum and Wyethia, also showed good response though the number of such cases was very low ( - Table 3 ).

LR was calculated for the frequently occurring symptoms of the four most frequently prescribed remedies ( - Table 4$)$. LR $>1$ indicates that there is an increased chance that a medicine will be effective if a certain symptom is present. By calculating LR, a comparative could be drawn, symptomwise, between these four remedies for COVID-19 cases. A blank in -Table 4 indicates that there was no patient responding well to this medicine when the symptom was present.

Arsenicum album showed meaningful LR for the symptoms running nose ( $\mathrm{LR}=3.07 ; 95 \% \mathrm{CI}, 1.27$ to 7.42 ) and anxiety ( $\mathrm{LR}=2.28 ; 95 \% \mathrm{CI}, 1.44$ to 3.59 ).

Bryonia alba showed meaningful LR for the symptoms dry cough ( $\mathrm{LR}=2.08$; $95 \% \mathrm{CI}, 1.52$ to 2.84 ), constipation ( $\mathrm{LR}=$ 6.56; $95 \% \mathrm{CI}, 2.69$ to 15.96 ), dryness of mouth and throat $(\mathrm{LR}=2.05 ; 95 \% \mathrm{CI}, 1.46$ to 2.87$)$ and increased thirst (LR $=1.88 ; 95 \% \mathrm{CI}, 1.28$ to 2.74$)$.

For the symptom fever, Gelsemium sempervirens had LR $=1.96$ and Pulsatilla nigricans had $\mathrm{LR}=1.02$, whilst Arsenicum album and Bryonia alba each had LR $<1$.

Gelsemium sempervirens showed meaningful LR for the symptoms fever ( $\mathrm{LR}=1.96 ; 95 \% \mathrm{Cl}, 1.37$ to 2.81 ), chills ( $\mathrm{LR}$ $=10.11,95 \% \mathrm{CI}, 5.29$ to 19.29$)$, decreased thirst $(\mathrm{LR}=7.35$; $95 \% \mathrm{CI}, 3.37$ to 16.02 ), decreased appetite ( $\mathrm{LR}=2.15 ; 95 \% \mathrm{CI}$, 
164 Homeopathic Remedies in COVID-19: Prognostic Factor Research Manchanda et al.

Table 2 Presenting complaints/symptoms $(n=211)$

\begin{tabular}{|l|l|l|}
\hline Symptom & $\begin{array}{l}\text { Number } \\
\text { of cases }\end{array}$ & Cases (\%) \\
\hline Fatigue & 100 & 47.4 \\
\hline Sore throat & 91 & 43.1 \\
\hline Dry cough & 83 & 39.3 \\
\hline Myalgia & 82 & 38.9 \\
\hline Fever & 80 & 37.9 \\
\hline Dry mouth and throat & 77 & 36.5 \\
\hline Increased thirst & 67 & 31.8 \\
\hline Headache & 65 & 30.8 \\
\hline Decreased appetite & 57 & 27.0 \\
\hline Anxiety & 52 & 24.6 \\
\hline Altered taste ${ }^{\text {a }}$ & 57 & 27.0 \\
\hline A sensation of heat in the body & 38 & 18.0 \\
\hline Productive cough & 35 & 16.6 \\
\hline Disturbed sleep & 34 & 16.1 \\
\hline Chest discomfort & 30 & 14.2 \\
\hline Loss of smell & 28 & 13.3 \\
\hline Dyspnea & 24 & 11.4 \\
\hline Constipation & 22 & 10.4 \\
\hline Decreased thirst & 19 & 9.0 \\
\hline Diarrhea & 18 & 8.5 \\
\hline Nausea & 13 & 6.2 \\
\hline Abdominal pain & 10 & 4.7 \\
\hline Flatulence & 8 & 3.8 \\
\hline Increased perspiration & 7 & 3.3 \\
\hline Vomiting & 5.4 \\
\hline
\end{tabular}

${ }^{\mathrm{a} T h i s ~ i n c l u d e s ~ d a t a ~ f o r ~ l o s s ~ o f ~ t a s t e . ~}$

1.31 to 2.54$)$, fatigue $L R=1.92 ; 95 \% \mathrm{CI}, 1.50$ to 2.48$)$, and myalgia ( $\mathrm{LR}=1.90 ; 95 \% \mathrm{CI}, 1.33$ to 2.73 ).

Pulsatilla nigricans showed meaningful LR for the symptoms altered taste ( $\mathrm{LR}=2.49 ; 95 \% \mathrm{CI}, 1.52$ to 4.07 ) and loss of smell ( $\mathrm{LR}=2.54 ; 95 \% \mathrm{CI}: 1.03$ to 6.23 ).

\section{Discussion}

In this study, homeopathic remedies seemed helpful in COVID19 patients in an integrated treatment regimen, even in cases with co-morbidities such as diabetes mellitus, hypertension, chronic kidney disease or hypothyroidism. No adverse reaction with any of the homeopathic medicines was observed. This disease presents a spectrum of symptoms ranging from fever and respiratory dysfunction to gastrointestinal complaints and loss of taste or smell. COVID-19, being a new disease, lacked any literature or past experience with the use of homeopathic remedies. Besides, in an epidemic, rare and peculiar symptoms are difficult to find. Therefore, prognostic factor research assumes importance wherein symptoms are regarded as factors that help in establishing the relationship between specific symptoms (prognostic factors) and
Table 3 Medicines prescribed $(n=211)$

\begin{tabular}{|l|l|}
\hline Medicine & Number of patients cured \\
\hline Arsenicum album & 61 \\
\hline Bryonia alba & 61 \\
\hline Gelsemium sempervirens & 19 \\
\hline Pulsatilla nigricans & 13 \\
\hline Belladonna & 11 \\
\hline Nux vomica & 8 \\
\hline Magnesia muriatica & 4 \\
\hline Ferrum phosphoricum & 3 \\
\hline Phosphorus & 3 \\
\hline Rhus toxicodendron & 3 \\
\hline Sulphur & 3 \\
\hline Camphora & 2 \\
\hline Causticum & 2 \\
\hline Chininum arsenicosum & 2 \\
\hline Kali carbonicum & 2 \\
\hline Mercurius solubilis & 2 \\
\hline Wyethia & 2 \\
\hline Antimonium tartaricum & 1 \\
\hline Argentum nitricum & 1 \\
\hline Calcarea carbonica & 1 \\
\hline Justicia adhatoda & 1 \\
\hline Kali muriaticum & 1 \\
\hline Lachesis mutus & 1 \\
\hline Lycopodium clavatum & 1 \\
\hline Mercurius corrosivus & 1 \\
\hline Sepia officinalis & 1 \\
\hline Spongia tosta & \\
\hline
\end{tabular}

medicines. ${ }^{20}$ This is done by calculating the LR of symptoms attributed to those homeopathic medicines that are found useful. Even common symptoms of a disease can assume importance if the LR of such symptoms is greater than 1 for a given remedy. Interestingly, LR also guides the confirmation of any remedy indicated for a set of symptoms.

Cases that are "false-positive cures", i.e., causality wrongly attributed to a remedy, cause underestimation of LR of a specific symptom for a specific remedy. ${ }^{21}$ Therefore, cases were selected based on selection criteria that also included the four domains of the Modified Naranjo Criteria that are relevant for acute diseases. Out of 327 cases reported, only 211 cases fulfilled the criteria and were analyzed.

The reliability and reproducibility of homeopathic prescriptions were assessed by calculating the LR of symptoms, medicine-wise. LR was estimated for symptoms attributed to the homeopathic remedies found useful. LR was considered and compared for the four most commonly prescribed homeopathic medicines. The medicine that showed high LR $(>1)$ for a symptom was considered for drawing 
Table 4 Likelihood ratio calculations for symptoms of four medicines

\begin{tabular}{|c|c|c|c|c|c|c|c|c|c|}
\hline Symptoms & Count & $\begin{array}{l}\text { Arsenicum } \\
\text { album }\end{array}$ & $\begin{array}{l}\text { LR } \\
\text { Ars }\end{array}$ & $\begin{array}{l}\text { Bryonia } \\
\text { alba }\end{array}$ & $\begin{array}{l}\text { LR } \\
\text { Bry }\end{array}$ & $\begin{array}{l}\text { Gelsemium } \\
\text { sempervirens }\end{array}$ & $\begin{array}{l}\text { LR } \\
\text { Gels }\end{array}$ & $\begin{array}{l}\text { Pulsatilla } \\
\text { nigricans }\end{array}$ & $\begin{array}{l}\text { LR } \\
\text { Puls }\end{array}$ \\
\hline & 211 & 61 & & 61 & & 19 & & 13 & \\
\hline Dry cough & 83 & 18 & 0.68 & 38 & 2.08 & 6 & 0.79 & 2 & 0.38 \\
\hline Productive cough & 35 & 9 & 0.85 & 7 & 0.61 & 3 & 0.95 & 4 & 1.97 \\
\hline Sore throat & 91 & 26 & 0.98 & 33 & 1.40 & 5 & 0.59 & 3 & 0.52 \\
\hline Fever & 80 & 23 & 0.99 & 23 & 0.99 & 13 & 1.96 & 5 & 1.02 \\
\hline Myalgia & 82 & 24 & 1.02 & 27 & 1.21 & 13 & 1.90 & 2 & 0.38 \\
\hline Headache & 65 & 13 & 0.61 & 24 & 1.44 & 8 & 1.42 & 5 & 1.27 \\
\hline Fatigue & 100 & 36 & 1.38 & 27 & 0.91 & 16 & 1.92 & 3 & 0.47 \\
\hline Constipation & 22 & 2 & 0.25 & 16 & 6.56 & & & 1 & 0.73 \\
\hline Sensation of heat in the body & 38 & 13 & 1.28 & 11 & 1.00 & 5 & 1.53 & 2 & 0.85 \\
\hline Abdominal pain & 10 & 3 & 1.05 & 3 & 1.05 & 1 & 1.12 & 1 & 1.69 \\
\hline Dry mouth and throat & 77 & 23 & 1.05 & 35 & 2.05 & 5 & 0.70 & 5 & 1.06 \\
\hline Chest discomfort & 30 & 8 & 0.89 & 13 & 1.88 & 2 & 0.72 & 2 & 1.09 \\
\hline Increased perspiration & 7 & 1 & 0.41 & 3 & 1.84 & 2 & 4.04 & & \\
\hline Anxiety & 52 & 25 & 2.28 & 7 & 0.38 & 9 & 2.12 & 2 & 0.61 \\
\hline Increased thirst & 67 & 27 & 1.66 & 29 & 1.88 & 1 & 0.15 & 1 & 0.23 \\
\hline Chills & 24 & 4 & 0.49 & & & 12 & 10.11 & 3 & 2.18 \\
\hline Dyspnea & 24 & 5 & 0.65 & 10 & 1.76 & 3 & 1.44 & 1 & 0.66 \\
\hline Loss of smell & 28 & 6 & 0.67 & 7 & 0.82 & & & 4 & 2.54 \\
\hline Flatulence & 8 & 1 & 0.35 & 3 & 1.48 & & & & \\
\hline Vomiting & 5 & 3 & 3.69 & 1 & 0.61 & & & & \\
\hline Blocked nose & 15 & & & 7 & 2.15 & 1 & 0.72 & 2 & 2.34 \\
\hline Nausea & 13 & 4 & 1.09 & 4 & 1.09 & 1 & 0.84 & 2 & 2.77 \\
\hline Decreased appetite & 57 & 15 & 0.88 & 17 & 1.05 & 10 & 2.15 & 5 & 1.46 \\
\hline Decreased thirst & 19 & 2 & 0.29 & 3 & 0.46 & 8 & 7.35 & 3 & 2.86 \\
\hline Altered taste & 57 & 10 & 0.52 & 26 & 2.06 & 4 & 0.76 & 8 & 2.49 \\
\hline Diarrhea & 18 & 5 & 0.95 & 4 & 0.70 & 1 & 0.59 & 1 & 0.90 \\
\hline Disturbed sleep & 34 & 14 & 1.72 & 7 & 0.64 & 4 & 1.35 & 1 & 0.46 \\
\hline Retrosternal burning & 10 & 3 & 1.05 & 2 & 0.61 & 1 & 1.12 & & \\
\hline Sneezing & 9 & 5 & 3.07 & 1 & 0.31 & & & & \\
\hline Running nose & 18 & 10 & 3.07 & 3 & 0.49 & & & 1 & 0.90 \\
\hline
\end{tabular}

symptomatology of that medicine in COVID-19. It also helped to differentiate between medicines with commonly occurring COVID-19 symptoms.

Comparisons were made among the four most frequently used medicines, based on LR and associated 95\% CI calculations: Arsenicum album was most indicated in COVID-19 cases presenting with anxiety and running nose; Bryonia alba was indicated in COVID-19 cases primarily presenting with a dry cough, with increased thirst, constipation, and dryness of the mouth; Gelsemium sempervirens will act better for symptoms of fever, chills, fatigue, decreased thirst, myalgia, and decreased appetite; Pulsatilla nigricans was more indicated in COVID-19 cases presenting with loss of taste and loss of smell.
In a study carried out in Hong Kong on 18 mild COVID-19 cases, Bryonia alba and Gelsemium sempervirens were indicated in four and 12 cases respectively. One of the homeopathic rubrics for Bryonia alba was "thirst for large quantities of water", similar to the observation in this study. For Gelsemium sempervirens, homeopathic rubrics were "weakness, chills and thirstlessness", similar to the observation in this study. ${ }^{22}$

An Italian public homeopathy clinic studied approximately 50 COVID-19 cases. In the first phase of the study, Arsenicum album was prescribed to patients with flu symptoms and to "boost their immune system". In the second phase, Bryonia alba and Gelsemium sempervirens gave good results in the private practice setting. ${ }^{23}$ An article on homeopathic clinical practice on COVID-19 cases in New York 
viewed this disease as appearing in stages or as having various clinical manifestations, each with its own main remedy. It shortlisted Gelsemium sempervirens, Senega and Antimonium arsenicosum as potentially curative remedies based on symptomatology and stages. ${ }^{24}$

A wide spectrum of medicines was used in the present study (-Table 3). Successful prescriptions are based on careful individualization of symptoms, either for an individual patient or collectively in epidemic outbreaks. ${ }^{25}$ Homeopathy has played a positive role in controlling epidemics afflicting humankind in the past, as in the Spanish flu pandemic of $1918 .^{26}$ These medicines have shown promising results for epidemic diseases such as cholera, influenza, dengue, and Japanese encephalitis. ${ }^{5,27-34}$

In a separate observational study at a COVID-19 health center at Nehru Homoeopathic Medical College, New Delhi, 196 patients were prescribed 28 remedies, out of which Bryonia alba, Arsenicum album, Pulsatilla nigricans, Nux vomica, Rhus toxicodendron and Gelsemium sempervirens were most frequently indicated (article in press). Four of these medicines are common to the present study.

The majority of COVID-19 cases (80\%) present mild symptoms and recover with general care and without developing any severe symptoms. ${ }^{35}$ Relevant selection criteria were therefore followed to rule out bias due to such instances. However, there is still a possibility that the database of cases with complete recovery can be attributed to causes other than the prescribed homeopathic medicine. Therefore, RCTs become even more important to prove the efficacy of medicines. The results of our study and other observational studies will be used for designing RCTs that test the effect of a group of selected homeopathic medicines.

\section{Conclusion}

Homeopathic medicines have shown encouraging results in COVID cases. The prescribing indications of Arsenicum album, Bryonia alba, Gelsemium sempervirens and Pulsatilla nigricans have been identified using prognostic factor research. This information will be useful for more accurate homeopathic prescribing to COVID-19 patients in future RCT research.

\section{Highlights}

- Clinical data were collected from contemporary homeopathic practice in integrated COVID-19 care centers in India.

- Prescribing indications of the four most frequently used homeopathic medicines, i.e., Arsenicum album, Bryonia alba, Gelsemium sempervirens and Pulsatilla nigricans, were identified using prognostic factor research.

- The findings may improve the accuracy of future homeopathic prescribing of COVID-19 patients.

\section{Authors' Contributions}

This study was conducted under the overall guidance of author R.K.M., who contributed toward planning, training of investigators, study design, and critical evaluation of data and manuscript, besides ensuring logistic support. Cases were treated and data sheets were completed by all co-authors. These authors also contributed toward critical review of the spreadsheet, data analysis, and subsequent review. Authors A.M., M.G., and B.S. helped in the development of study design, statistical analysis, manuscript writing, and data collection coordination. All authors are responsible for and agreed to the content of the manuscript.

\section{Funding}

Indian Government infrastructure was used. No special funding was provided as all the contributors are full-time staff employed by the Government of NCT of Delhi.

Conflict of Interest

None declared.

\section{Acknowledgments}

We extend our sincere gratitude to Shri Satyendra Jain, Minister of Health and Family Welfare, Government of NCT of Delhi, for providing an opportunity for this study. We are grateful to $\mathrm{M} / \mathrm{s}$ Wilmar Schwabe India Ltd., India, for providing GMP-certified homeopathic remedies for use on COVID-19 patients. We acknowledge the contributions of Dr. Anurag Pandey, Dr. Amit Arora, Dr. Akhil Gupta, Dr. Shirin Balan, Dr. Smita Brahmachari, Dr. Shruti Gora, Dr. Udesh Kumar, Dr. Abakash Barik, and Dr. Mikhita B. Moon in data collection. We are thankful to Dr. Lex Rutten for teaching prognostic factor research. We also thank Dr. Kamal Rawal at Amity University for his inputs in data collection. We are also obligated to our patients for their willing cooperation.

\section{References}

1 India confirms its first coronavirus case. Accessed August 1, 2020 at: https://www.cnbc.com/2020/01/30/india-confirmsfirst-case-of-the-coronavirus.html

2 Kaur H, Chalia DS, Manchanda RK. Homeopathy in public health in India. Homeopathy 2019;108:76-87

3 Manchanda RK, Kaur H. Medical pluralism in health care-experience from New Delhi. In: Robert Jütte, ed. Medical Pluralism: Past, Present, Future. Stuttgart: Franz Steiner Verlag; 2013:189-194

4 Chakraborty P, Lamba C, Nayak D, et al. Effect of individualized homoeopathic treatment in influenza like illness: a multicenter, single blind, randomized, placebo controlled study. Indian J Res Homoeopathy 2013;7:22-30

5 Frei H. H1N1 influenza: a prospective outcome study with homeopathy and polarity analysis. Am J Hom Med 2014;107:114-122

6 Oberbaum M. Will we miss the opportunity again? Homeopathy 2020;109:176-178

7 Basu N, Das BC, Tandon S. Interim management of COVID-19 by repurposed homeopathic medicines. Homeopathy 2020; 109:182-183

8 Teut M, Walach $\mathrm{H}$, Varanasi R, et al. Recommendations for designing, conducting and reporting observational studies in homeopathy. Homeopathy 2020;109:114-125

9 Miglani A, Rutten L, Manchanda RK. Generalisability of prognostic factor research: further analysis of data from the IIPCOS2 study. Homeopathy 2017;106:155-159 
10 Rutten L. Prognostic factor research in homoeopathy. Indian J Res Homoeopathy 2016;10:59-65

11 Ministry of AYUSH. Notification to Be Published in the Extraordinary Gazette of India, No. L.11011/8/2020/AS. New Delhi: Ministry of AYUSH, Government of India; 2020

12 Priya R, Sujatha V. AYUSH for COVID-19: science or superstition? Indian J Public Health 2020;64:S105-S107

13 Guan W-J, Ni Z-Y, Hu Y, et al. Clinical characteristics of coronavirus disease 2019 in China. N Engl J Med 2020; 382:1708-1720

14 Clinical Management protocol: COVID-19. Accessed August 1, 2020 at https://www.mohfw.gov.in/pdf/ClinicalManagementProtocolforCOVID19dated27062020.pdf

15 Ho CS, Chee CY, Ho RC. Mental health strategies to combat the psychological impact of COVID-19 beyond paranoia and panic. Ann Acad Med Singapore 2020;49:155-160

16 Miglani A. Effect of lockdown during COVID-19: an Indian perspective. Int J Sci Healthcare Res 2020;5:55-61

17 Reilly D, Mercer SW, Bikker AP, Harrison T. Outcome related to impact on daily living: preliminary validation of the ORIDL instrument. BMC Health Serv Res 2007;7:139

18 van Haselen RA. Homeopathic clinical case reports: development of a supplement (HOM-CASE) to the CARE clinical case reporting guideline. Complement Ther Med 2016;25:78-85

19 Revised discharge policy for COVID-19.pdf. Accessed August 1, 2020 at: http://health.delhigovt.nic.in/wps/wcm/connect/ b6af6e004e9fefb89ce8bd5dc9149193/Order11620.pdf?MOD-

$=$ AJPERES\&Imod $=-1471732290 \&$ CACHEID $=$ b6af6e004e9fefb89 ce8bd5dc9149193

20 Riley RD, Hayden JA, Steyerberg EW, et al; PROGRESS Group. Prognosis Research Strategy (PROGRESS) 2: prognostic factor research. PLoS Med 2013;10:e1001380

21 Rutten L. Data collection: treat every variable as a treasure. Homeopathy 2015;104:190-196

22 To KLA, Fok YYY. Homeopathic clinical features of 18 patients in COVID-19 outbreaks in Hong Kong. Homeopathy 2020; 109:146-162
23 Rossi EG. The experience of an Italian public homeopathy clinic during the COVID-19 epidemic, March-May 2020. Homeopathy 2020;109:167-168

24 Masiello DJ. The COVID-19 pandemic: a view from New York city. Homeopathy 2020;109:163-166

25 Waisse S, Oberbaum M, Frass M. The Hydra-headed coronaviruses: implications of COVID-19 for homeopathy. Homeopathy 2020;109:169-175

26 Shinde V. Homoeopathy in pandemic Spanish flu 1918. Indian J Res Homoeopathy 2020;14:152-159

27 Aparecida L, Nunes S. Contribution of homeopathy to the control of an outbreak of dengue in Macaé, Rio de Janeiro. Int J High Dilution Res 2008;7:186-192

28 Oberai P, Varanasi R, Padmanabhan M, et al. Effectiveness of homeopathic medicines as add-on to institutional management protocol for acute encephalitis syndrome in children: an openlabel randomized placebo-controlled trial. Homeopathy 2018; 107:161-171

29 Hoover TA. Homeopathic prophylaxis: fact or fiction. J Am Inst Homeopath 2001;94:168-175

30 Shalts E. Consistently proven effective. In: The American Institute of Homeopathy Handbook for Parents. San Francisco: Jossey-Bass; 2005:33-40

31 von Bönninghausen CM, ed. Brief instructions for non-physicians concerning the prophylaxis and treatment of Asiatic cholera. In: The Lesser Writings of C.M.F. von Boenninghausen. Rep ed. New Delhi: Jain Publishers; 2005:299-308

32 Shepherd D. Homoeopathy in epidemic diseases. Saffron Walden: C.W. Daniel Company Ltd.; 1996

33 Marino R. Homeopathy and collective health: the case of dengue epidemics. Int J High Dilution Res 2008;7:179-185

34 Chaudhary A, Khurana A. A review on the role of homoeopathy in epidemics with some reflections on COVID-19 (SARS-CoV-2). Indian J Res Homoeopathy 2020;14:100-109

35 Dos Santos WG. Natural history of COVID-19 and current knowledge on treatment therapeutic options. Biomed Pharmacother 2020;129:110493 